\title{
Indometacin inhibits the proliferation and activation of human pancreatic stellate cells through the downregulation of COX-2
}

\author{
LIANKANG SUN $^{1}, \mathrm{KE} \mathrm{CHEN}^{1}, \mathrm{ZHENGDONG} \mathrm{JIANG}^{1}, \mathrm{XIN} \mathrm{CHEN}^{1}$, JIGUANG MA ${ }^{2}$, \\ QINGYONG $\mathrm{MA}^{1}$ and WANXING DUAN ${ }^{1}$ \\ Departments of ${ }^{1}$ Hepatobiliary Surgery and ${ }^{2}$ Anesthesiology, First Affiliated Hospital, \\ Xi'an Jiaotong University, Xi'an 710061, P.R. China
}

Received August 13, 2017; Accepted February 6, 2018

DOI: $10.3892 /$ or.2018.6321

\begin{abstract}
Increasing evidence indicates that pancreatic stellate cells (PSCs) are responsible for the stromal reaction in pancreatic ductal adenocarcinoma (PDAC). The interaction between activated PSCs and PDAC cells and the resultant stromal reaction facilitate cancer progression. Previous findings suggested that cyclooxygenase-2 (COX-2) may have a profound role in regulating the proliferation and activation of PSCs in response to pancreatic cancer. Indometacin, a well-known anti-inflammatory drug and a non-selective inhibitor of COX-2, has been shown to exert anticancer effects in various types of cancer, including PDAC. However, whether indometacin affects PSC activation remains unclear. Using RT-qPCR and western blot analysis, we determined that COX-2 expression was elevated in tandem with the activation of PSCs. Treatment with indometacin suppressed the viability and the migration ability of PSCs in a dose-dependent manner. In addition, the immunoblotting and immunofluorescence results showed that $\alpha$-SMA expression was markedly decreased by indometacin. A further study indicated that COX-2 expression was decreased in PSCs after indometacin intervention. In conclusion, these data indicate that indometacin serves as an effective drug against PSC activation via the targeting of COX-2.
\end{abstract}

Correspondence to: Dr Qingyong Ma or Dr Wanxing Duan, Department of Hepatobiliary Surgery, First Affiliated Hospital, Xi'an Jiaotong University, 277 West Yanta Road, Xi'an 710061, P.R. China

E-mail: qyma56@xjtu.edu.cn

E-mail: 15339184808@163.com

Key words: pancreatic ductal adenocarcinoma, pancreatic stellate cells, COX-2, indometacin, desmoplastic reaction

\section{Introduction}

Pancreatic ductal adenocarcinoma (PDAC) is a lethal malignancy whose overall five-year survival rate remains at less than 7\%, and PDAC remains the fourth highest cause of cancer-related mortality worldwide (1). One of the most conspicuous histopathologic features of PDAC is a highly desmoplastic reaction, which is characterized by activated pancreatic stellate cells (PSCs) and a major accumulation of extracellular matrix (ECM) $(2,3)$. Accumulating evidence indicates that the desmoplastic stroma enhances stiffness, hyaluronic acid content and intratumoral hydrostatic pressures, and produces solid-stress pressure derived from solid tissue components, which may result in the compression of tumor vessels, thus causing heterogeneous tumor perfusion in pancreatic cancer $(4,5)$. Consequently, this desmoplastic stroma is believed to contribute to hypoxia and to hinder the effective intratumoral drug delivery and therapeutic efficacy, leading to poorer treatment outcomes (6).

PSCs are nestin-positive and lipid-storing cells in the pancreas that have been shown to have a profound role in normal ECM turnover (7,8). In healthy states, non-activated PSCs contain abundant cytoplasmic lipid droplets, which are rich in vitamin A, and produce very low levels of ECM (9). When stimulated by inflammation or injury of the pancreas, quiescent PSCs, which contain abundant lipid droplets, trans-differentiate into 'activated' myofibroblast-like cells characterized by an increased expression of $\alpha$-smooth muscle actin ( $\alpha$-SMA) as well as by the enhanced synthesis of matrix components, such as fibronectins and collagens. PSCs are also thought to play a vital role in the pathobiology of pancreatic cancer. In PDAC, a reciprocal supportive role between pancreatic cancer cells and activated PSCs is increasingly being investigated: Pancreatic cancer cells secrete pro-mitogenic and pro-fibrogenic factors, including sonic hedgehog $(\mathrm{SHH})$, transforming growth factor- $\beta$ (TGF- $\beta$ ), and platelet-derived growth factor (PDGF), which promote PSC activation $(9,10)$. Reciprocally, activated PSCs facilitate PDAC progression by providing materials and energy, thereby creating a favorable microenvironment for pancreatic cancer cells (11). The above mentioned findings indicated that PSCs, the predominant fibroblastic cell type in 
the PDAC microenvironment, may be a potential therapeutic target. However, mechanisms to target PSCs that can reverse their activation and block their reciprocal role in pancreatic cancer remain poorly understood. Prostaglandin-endoperoxide synthase, generally known as cyclooxygenase (COX), is the rate-limiting enzyme that catalyzes the conversion of arachidonic acid (AA) to prostaglandin E2, which occurs via microsomal PGE2 synthases (12). Cyclooxygenase has three isoforms known as COX-1, COX-2 and COX-3 (a splice variant of COX-1). Previous studies have proven that COX-2 is highly expressed in chronic pancreatitis, pancreatic intraepithelial neoplasia (PanIN) and pancreatic adenocarcinoma (13-18). In a transgenic mouse model of PDAC, it has been demonstrated that the inflammation induced by a high-fat diet promotes the expression of COX-2, elevates the activity of Kras and leads to the development of fibrosis during the progression from PanIN to PDAC (19). Immortalized human pancreatic stellate cells (HPSCs) express COX-2 as well and synthesize PGE2. Through its EP4 receptor, PGE2 stimulates the proliferation and migration of HPSCs and enhances the synthesis of ECM and MMP genes (20). Indometacin, a well-known anti-inflammatory drug and a non-selective inhibitor of cyclooxygenase-2 (COX-2), has previously been shown to have anticancer activities against many types of neoplastic diseases (21-24). The mechanism by which these anticancer activities occur may be through suppression of cell growth and induction of apoptosis (16). Our previous findings also showed that indometacin can reverse the invasion and proliferation that is induced by high levels of glucose though the regulation of E-cadherin in pancreatic cancer cells (25). However, despite the strong correlation between the expression of COX-2 and pancreatic fibrosis, the mechanism involved in the inhibitory role of indometacin in COX-2-mediated effects on PSCs remains unclear.

In the present study, we hypothesized that indometacin, as an anti-inflammatory drug, can inhibit PSC proliferation and migration and suppress its activation through the inhibition of COX-2, thus potentially blocking bidirectional interaction between PDAC cells and PSCs. To test this hypothesis in the present study, we used human PSCs obtained and purified from the surgically resected tumor tissue of patients suffering from pancreatic cancer, and we determined the effect of indometacin on the proliferation, migration and activation of human PSCs, in addition to the underlying mechanism.

\section{Materials and methods}

Ethics approval and patient consent. All the experimental protocols were authorized by the Ethics Committee of the First Affiliated Hospital of Medical College, Xi'an Jiaotong University (Xi'an, China). The protocols also complied with the Declaration of Helsinki. Written informed consent was obtained from all the study participants. Only adults were included in this study.

Cell culture and reagents. Human PSCs were separated from surgically resected tumor tissue using the outgrowth method. The tumor tissues were collected from the Department of Hepatobiliary Surgery at the First Affiliated Hospital of $\mathrm{Xi}$ 'an Jiaotong University. The isolated PSCs were cultured according to methods described in previous studies $(26,27)$ and grown in F12/DMEM enriched with $10 \%$ fetal bovine serum, penicillin $\mathrm{G}(100 \mathrm{U} / \mathrm{ml})$, and streptomycin $(100 \mu \mathrm{g} / \mathrm{ml})$ in a humidified atmosphere of $5 \% \mathrm{CO}_{2}$ at $37^{\circ} \mathrm{C}$. The purity of the PSCs was estimated by morphology, Oil red $\mathrm{O}$ staining of intracellular fat droplets, and immunofluorescence of $\alpha$-smooth muscle actin (Fig. 1). Cell culture media were obtained from Gibco-BRL (Grand Island, NY, USA). Indometacin, dimethyl sulfoxide (DMSO), and 3-(4,5-dimethylthiazol-2-yl)-2, 5-diphenyltetrazolium bromide (MTT) were obtained from Sigma Chemicals (St. Louis, MO, USA). The stock solution of indometacin was dissolved in DMSO at $50 \mathrm{~g} / \mathrm{l}$. The antibodies used in this study included anti-COX-2 (Cell Signaling Technology, Danvers, MA, USA), anti- $\alpha-S M A$ (Sigma, St. Louis, MO, USA), and anti- $\beta$-actin (Santa Cruz Biotechnology, Santa Cruz, CA, USA).

Cell viability assay. Human PSCs obtained from pancreatic cancer patients were seeded at $5 \times 10^{3}$ cells per well into 96 -well plates and treated with indometacin at a concentration gradient $(0,10,20,50,100$ and $200 \mathrm{mg} / \mathrm{l})$ for $48 \mathrm{~h}$. Subsequently, the MTT assay was applied to assess the cell viability, and the absorbance of $490 \mathrm{~nm}$ by a multiwall microplate reader (Bio-Rad, Richmond, CA, USA) was used for the assessment.

Transwell-migration assay. Assays were performed to assess human PSC migration by Transwell chambers (Millipore, Billerica, MA, USA) in accordance with the protocol described previously (28). Briefly, human PSCs were serum-starved for 6-8 $\mathrm{h}$, and then indometacin was used to pretreat the cells for 24 h. Subsequently, PSCs $\left(1 \times 10^{5}\right)$ were digested, resuspended in serum-free medium and seeded into an upper chamber of a Transwell plate. The PSCs were given $24 \mathrm{~h}$ to migrate into the lower chamber containing a $10 \%$ serum gradient. After $24 \mathrm{~h}$, the non-migratory cells on the upper side were scraped using a cotton swab, and the membrane of the chamber was then fixed with $4 \%$ paraformaldehyde and stained with $0.1 \%$ crystal violet. The number of migrated cells on each membrane in 10 random fields was counted, imaged and recorded at a magnification of $\mathrm{x} 100$. The values reported here are the averages of triplicate experiments.

Reverse transcriptase-quantitative PCR (RT-qPCR). After completion of the specified intervention, total ribonucleic acid (total RNA) was extracted from these cells using Trizol reagent (Invitrogen, Carlsbad, CA, USA) according to the manufacturer's protocol. The extracted total RNA was then reverse-transcribed into cDNA using a PrimeScript RT reagent kit (Takara Biotechnology, Dalian, China). An iQ5 multicolor real-time PCR detection system (Bio-Rad, Hercules, CA, USA) and a SYBR-Green PCR kit (Takara Biotechnology) were used for qPCR according to the manufacturer's protocols. The following PCR program was used: Denaturation at $95^{\circ} \mathrm{C}$ for $30 \mathrm{sec}$, followed by 40 cycles consisting of denaturation at $95^{\circ} \mathrm{C}$ for $5 \mathrm{sec}$, annealing at $60^{\circ} \mathrm{C}$ for $30 \mathrm{sec}$, and extension at $72^{\circ} \mathrm{C}$ for $30 \mathrm{sec}$. The specificity of the amplified PCR products was evaluated by melting curve analysis, and the comparative $\mathrm{C}(\mathrm{q})$ method, with GAPDH as the normalization control, was used to assess the expression level of each target gene, as previously described (29). The primer sequences used for 
A

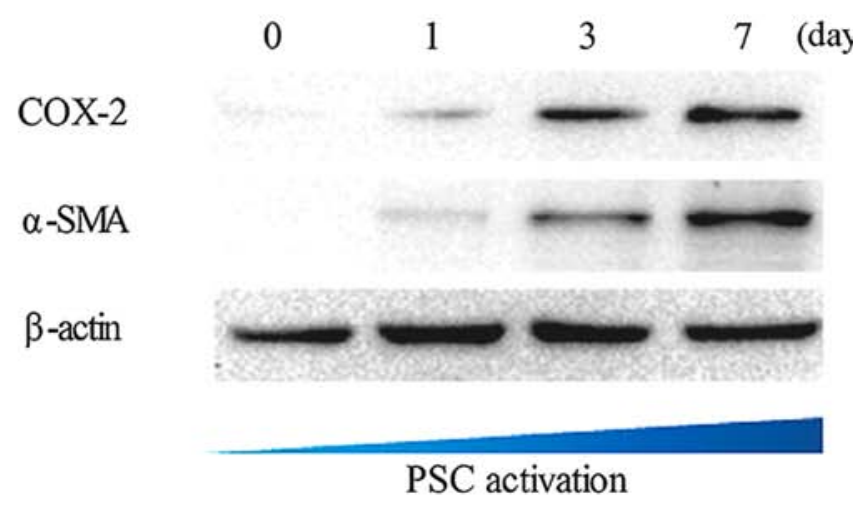

B Quiescent PSC
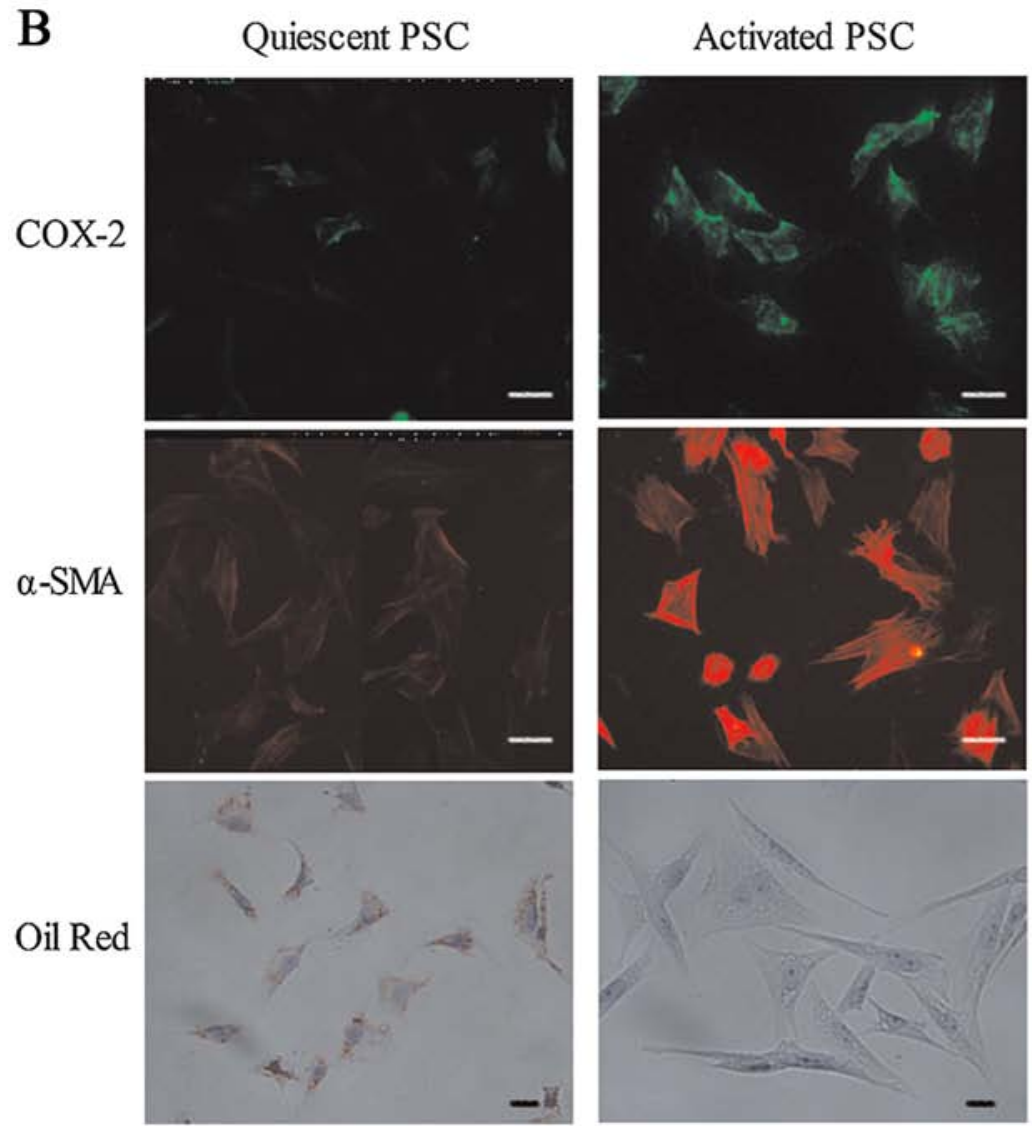

Figure 1. Expression of COX-2 in human pancreatic stellate cells (hPSCs). (A) Western blot analysis verified that the protein expression level of COX-2 was increased during PSC activation. $\alpha$-SMA was used as a marker of PSC activation, and $\beta$-actin was used as an internal loading control. (B) Representative images showing COX-2, $\alpha$-SMA expression in quiescent/activated PSC by using immunofluorescence and lipid droplets by using Oil red staining. Scale bar, $50 \mu \mathrm{m}$; the magnification of Oil red staining is $\mathrm{x} 200$ and that of immunofluorescence staining is $\times 400$.

RT-qPCR were: For COX-2 sense, 5'-TTCAAATGAGATTGT GGGAAAATTGCT-3' and antisense, 5'-GTGCATCAACAC AGGCGCCTCTTC-3'; and for $\beta$-actin sense, 5'-ATCGTG CGTGACATTAAGGAGAAG-3' and antisense, 5'-AGGAAG GCTGGAAGAGTG-3'.

Western blot analysis. Total protein was extracted from $1 \times 10^{6}$ PSCs grown under the above experimental conditions using RIPA lysis buffer (Beyotime, Guangzhou, China). The BCA protein assay kit (Pierce Biotechnology, Rockford, IL, USA) was used to test the concentration of the proteins based on the manufacturer's instructions. The details of the western blot assay were previously described (30). The expression of specific proteins was determined using a peroxidase reaction to visualize the chemiluminescence of immunoreactive bands, and the images of the bands were recorded by the ChemiDoc XRS imaging system (Bio-Rad). Quantity One image software (version 4.6; Bio-Rad) was used for the densitometric analysis of each band, and $\beta$-actin was used as the internal loading control.

Immunofluorescence microscopy. After a specific intervention was completed, PSCs were washed with phosphate-buffered saline (PBS) and fixed in 4\% paraformaldehyde for $30 \mathrm{~min}$ at room temperature, washed with PBS again, and permeabilized in $0.5 \%$ Triton X-100 (diluted in PBS) for $10 \mathrm{~min}$. The cells on the slides were subsequently blocked with $5 \%$ BSA for $1 \mathrm{~h}$ at room temperature, and then incubated with the 


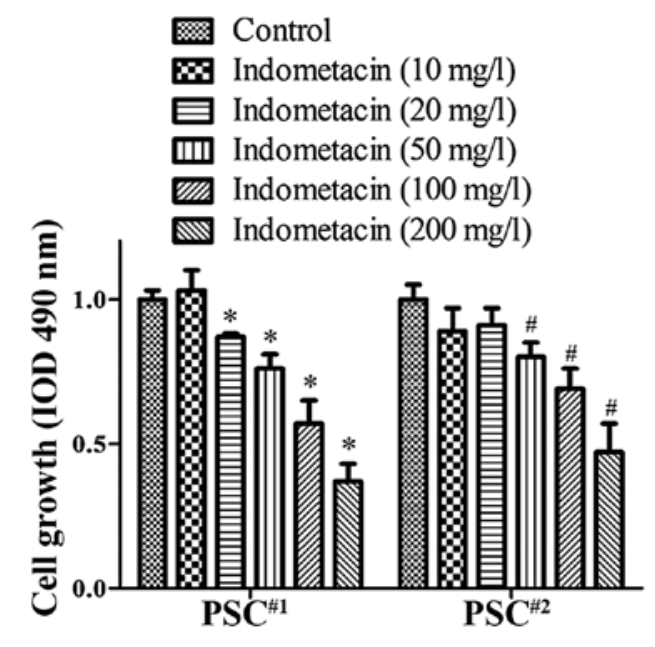

Figure 2. Effects of indometacin on the viability of hPSCs. hPSCs were were treated with different concentrations $(0,10,20,50,100$, and $200 \mathrm{mg} / \mathrm{l})$ of indomethacin for $48 \mathrm{~h}$, and cell viability was assessed using an MTT assay. The results show that the viability of hPSCs was impaired by indometacin. ${ }^{*}, \mathrm{P}<0.05$ compared with the control group. The data shown are representative of three independent experiments. The mean values and standard deviations in the graphs are calculated from three experiments with a total of 5 samples per treatment group.

primary antibody [COX-2 (D5H5); Cell Signaling Technology, Danvers, MA, USA, rabbit monoclonal antibody, dilution at 1:100, cat. no. 12282; $\alpha$-SMA; Sigma, St. Louis, MO, USA; mouse monoclonal antibody, dilution at 1:200, cat. no. A5228] at $4^{\circ} \mathrm{C}$ overnight. Following incubation with the secondary antibody [Alexa Fluor 488-conjugated goat anti-rabbit IgG (green), dilution at 1:200; Alexa Fluor 488-conjugated goat anti-mouse IgG (green), dilution at 1:200; Alexa Fluor 594-conjugated goat anti-mouse IgG (red), dilution at 1:200] from Jackson Immunoresearch Laboratories (West Grove, PA, USA) for $1 \mathrm{~h}$ at room temperature, the cell nuclei were stained with 4'-6-diamidino-2-phenylindole (DAPI) and then sealed on the glass slides. A Zeiss Instruments confocal microscope (Carl Zeiss Microscopy; LLC, Thornwood, NY, USA) was used to capture images and record the cells on the slides using appropriate excitation and emission spectra at a magnification of $\times 400$.

Oil red $O$ staining. Oil red $\mathrm{O}$ staining was applied to visualize intracellular lipid content in PSCs. Briefly, PSCs on the slides were washed with phosphate-buffered saline (PBS) and fixed in $4 \%$ paraformaldehyde for $1 \mathrm{~h}$ at room temperature. After washing the PSCs with isopropanol, pre-warmed $0.25 \%$ oil red $\mathrm{O}$ working solution was used to stain intracellular lipid content for $15 \mathrm{~min}$ in a $60^{\circ} \mathrm{C}$ oven. After being washed with PBS twice, the cells were re-stained with hematoxylin for $15 \mathrm{sec}$ and sealed with glycerin on glass slides. Finally, a light microscope (Nikon Eclipse Ti-S; Nikon Corporation, Tokyo, Japan) at a magnification of $\times 200$ was used to photograph the cells stained with oil red $\mathrm{O}$.

Statistical analysis. The data shown in this study were representative of three independent experiments, for each experiment, at least 3 samples were used in each treatment group. Data are presented as the means \pm standard deviation.
Differences between groups were evaluated using one-way analysis of variance (ANOVA) and post hoc analysis of significant effects was performed using Dunnett's test. $\mathrm{P}<0.05$ was considered statistically significant.

\section{Results}

COX-2 levels are elevated during PSC activation when cultured in vitro. We extracted protein from PSCs at various stages (after 0, 1, 3 or 7 days of culture) of activation for western blot analysis. As shown in Fig. 1A, during the process of activation of PSCs that were cultured in vitro, the expression of COX-2 and $\alpha$-SMA simultaneously increased with the increasing culture time, while the cytoplasmic lipid droplets in PSCs were substantially decreased, as determined by oil red $\mathrm{O}$ staining (Fig. 1B). The immunofluorescence staining in Fig. 1B revealed cytoplasmic staining for COX-2 in cells that were also $\alpha$ SMA-positive. The fluorescence intensity of COX-2 and $\alpha$-SMA in activated PSCs was higher than that in quiescent PSCs. These results showed that COX-2 levels are elevated during PSC activation when cultured in vitro.

Indometacin restrains the proliferation of human PSCs. To explore the effect of indometacin on PSCs, we first investigated the effect of indometacin on the proliferation of these cells using an MTT assay. PSCs were taken from patients with pancreatic cancer were treated with a series of gradually increasing concentrations of indometacin ( 0 as a control, then $10,20,50,100$, or $200 \mathrm{mg} / \mathrm{l}$ ) for $48 \mathrm{~h}$. Our results showed that indometacin decreased the growth rate of human PSCs in a dose-dependent manner (Fig. 2). The statistical analysis showed that indometacin started to inhibit the proliferation of all human PSCs at a concentration of $50 \mathrm{mg} / \mathrm{l}$, and the cell growth rate was significantly decreased at a concentration of $200 \mathrm{mg} / \mathrm{l}$. According to the data from the MTT assays, we chose the concentrations of 50 and $100 \mathrm{mg} / \mathrm{l}$ for further experiments.

Indometacin inhibits the migration of human PSCs. Next, we studied the effect of indometacin on the migration of human PSCs using Transwell-migration assays. As shown in Fig. 3, treatment with $50 \mathrm{mg} / 1$ indometacin markedly decreased the migration ability of human PSCs compared to the untreated cells in the control group, and almost no cells migrated with an indometacin concentration of $100 \mathrm{mg} / \mathrm{l}$. The statistical analysis showed that there was a significant difference in the migration ability between the untreated control cells and PSCs treated with indometacin. These results suggested that indometacin inhibits the migration capacity of human PSCs obtained from pancreatic cancer patients in vitro.

Indometacin inhibits human PSCs activation. To determine the effect of indometacin on PSC activation, we treated human PSCs with indometacin in vitro. The serum-free starvation-synchronized PSCs were treated with indometacin ( 50 or $100 \mathrm{mg} / \mathrm{l}$ ) for $24 \mathrm{~h}$. Subsequently, PSC activation was verified by the detection of $\alpha$-SMA level using western blot analysis and immunofluorescence staining. As shown in Fig. 4A and B, the western blot results indicated that indometacin decreased the expression of $\alpha$-SMA in a dose-dependent manner. The 

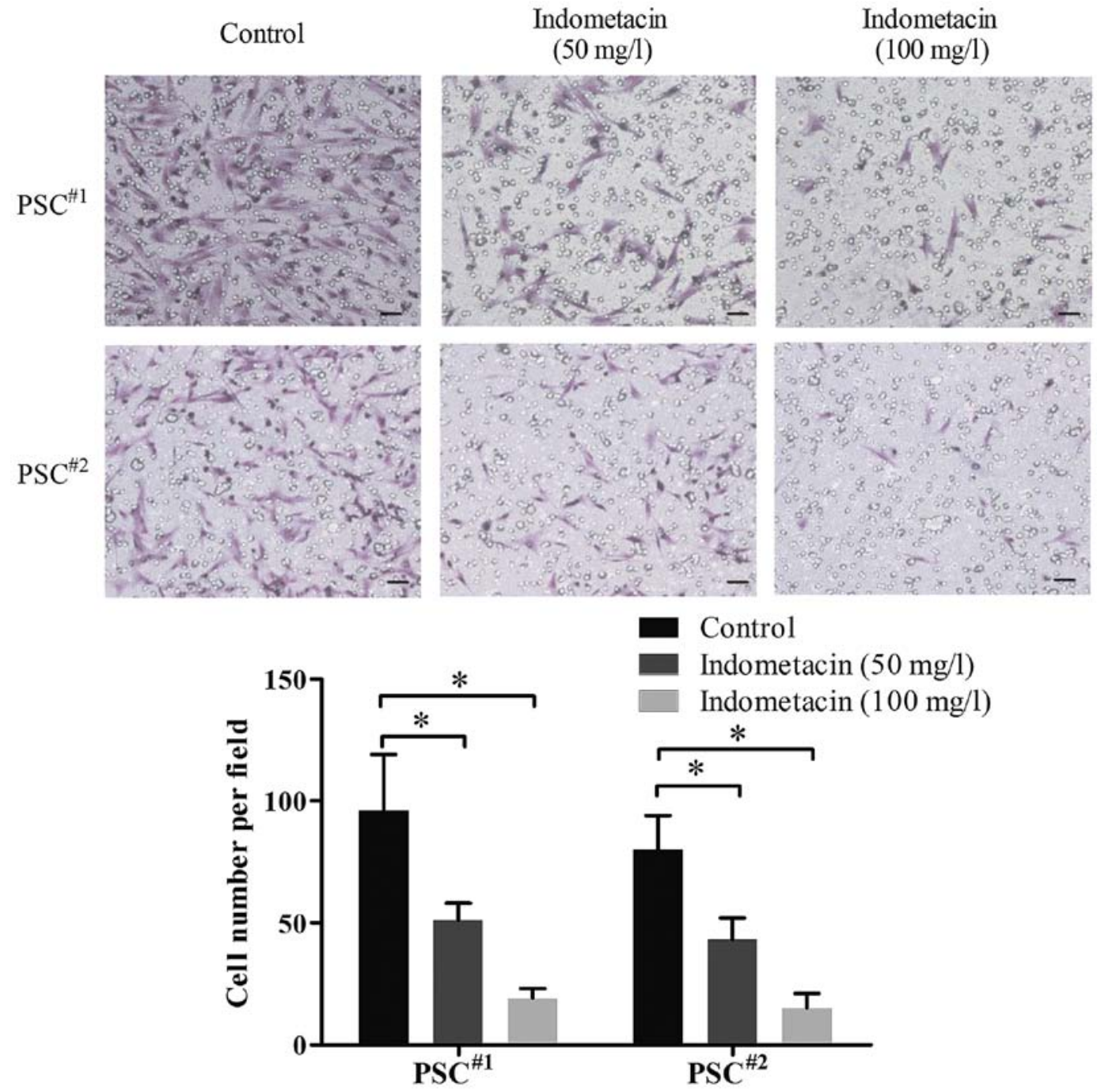

Figure 3. Effects of indometacin on the migration of hPSCs. Transwell-migration assays were performed to detect the effect of indometacin on the migration ability of hPSCs. The migrated cells were quantified by counting the number of cells in 10 random fields. " $\mathrm{P}<0.05$; Columns, mean; bars, SD. The data are representative of at least three independent experiments. The mean values and standard deviations in the graphs are calculated from three experiments with a total of 3 samples per treatment group. Scale bar, $50 \mu \mathrm{m}$; magnification, $\mathrm{x} 100$.

$\alpha$-SMA level was significantly lower in cells treated with $100 \mathrm{mg} / \mathrm{l}$ indometacin than in untreated cells in the control group. Similarly, immunofluorescence labeling showed that treatment with $100 \mathrm{mg} / \mathrm{l}$ indometacin markedly decreased the $\alpha$-SMA level (Fig. 4C).

Indometacin suppresses PSC activation through the downregulation of $C O X-2$ expression. To determine whether indometacin affected PSC activation via inhibition of the expression of COX-2, human PSCs were treated with indometacin (at concentrations of $0,10,20,50,100$ or $200 \mathrm{mg} / \mathrm{l}$ ) for $24 \mathrm{~h}$. Total cell RNA was extracted to evaluate the mRNA levels of COX-2 by RT-qPCR. Similarly, the cells were treated with indometacin (at concentrations of $0,10,20,50$ or $100 \mathrm{mg} / \mathrm{l}$ ) for $48 \mathrm{~h}$, and COX-2 protein expression was determined by western blot analysis in human PSCs. The findings are shown in Fig. 5A-C. Indometacin treatment decreased COX-2 expression at the mRNA and protein levels in a dose-dependent manner. To further investigate indometacin suppression of PSC activation via the inhibition of COX-2, immunofluorescent double staining was used to synchronously visualize COX-2 expression and PSC activation. As shown in Fig. 5D, the immunofluorescence results show that the level of PSC activation and the expression of COX-2 were simultaneously decreased at an indometacin concentration of $100 \mathrm{mg} / \mathrm{l}$. These results demonstrated that indometacin suppresses PSC activation to some extent through the downregulation of COX-2 expression.

\section{Discussion}

As Dvorak noted, cancers are similar to wounds that do not heal (2), and accumulating evidence has shown that a reactive stroma microenvironment exerts a supportive role on PDAC progression $(31,32)$. PSCs are the main components of this reactive stroma. In the initiation and development of pancreatic cancer, stellate cells in a quiescent state undergo phenotypic changes that transdifferentiate them from vitamin-A-rich cells into 'activated' PSCs that overexpress $\alpha$-SMA and that synthesize large amounts of extracellular matrix components, 


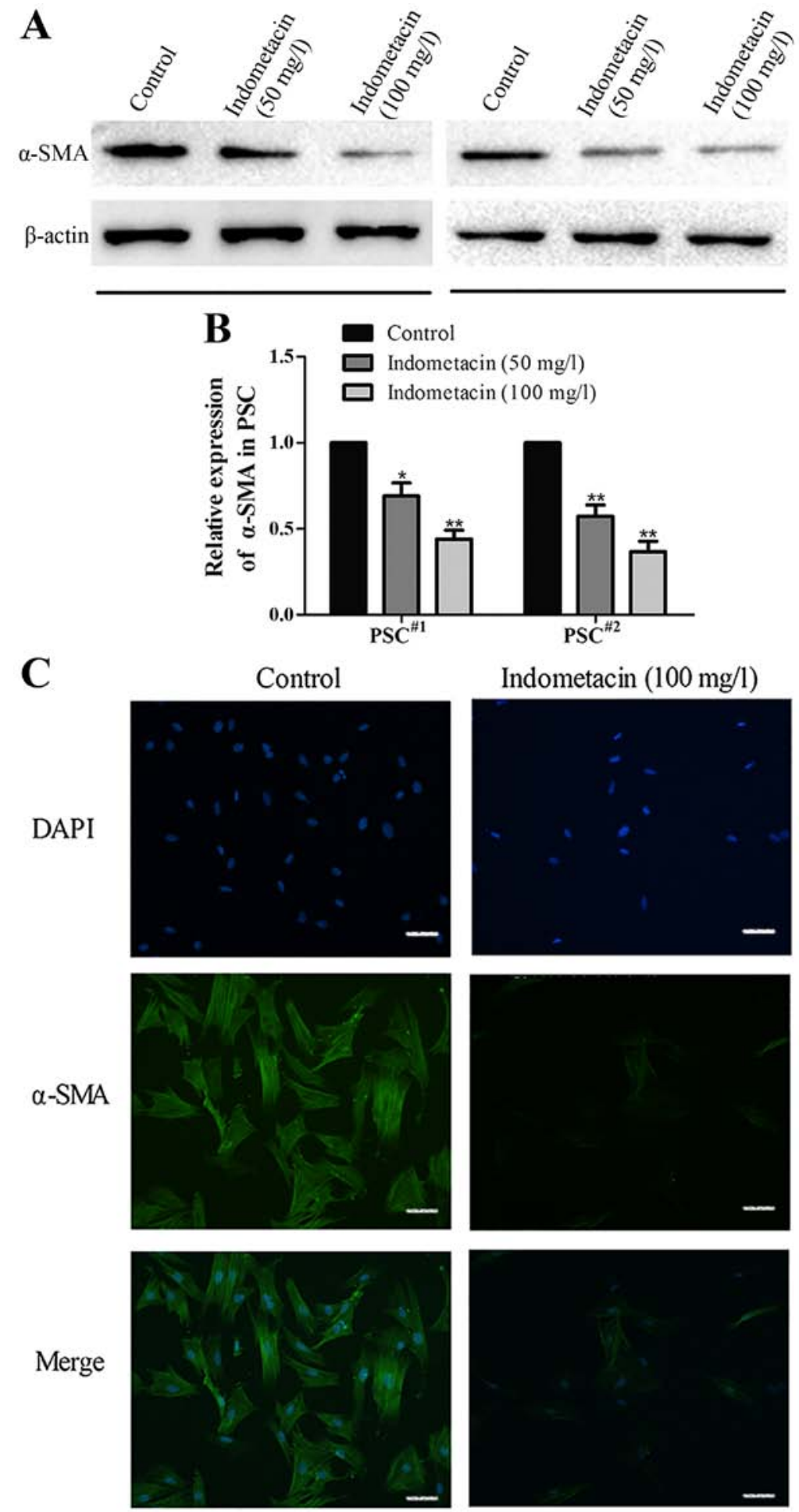

Figure 4. Indometacin inhibits the activation of hPSCs. (A) Western blot analysis was performed to detect the $\alpha$-SMA expression in hPSCs after cells were treated with indometacin $(0,100$ and $200 \mathrm{mg} / \mathrm{l})$ for $48 \mathrm{~h}$. (B) Gray scanning analysis was conducted by Quantity One image software to quantify the relative expression of $\alpha$-SMA with regard to $\beta$-actin in (A). ${ }^{*} \mathrm{P}<0.05,{ }^{* * *} \mathrm{P}<0.01$ compared with the control group. The data are representative of at least three independent experiments. (C) The $\alpha$-SMA expression in hPSCs was detected by immunofluorescence analysis after $100 \mathrm{mg} / 1$ indometacin intervention. Scale bar, $50 \mu \mathrm{m}$; magnification, $\mathrm{x} 400$.

such as fibronectin and collagens; these components form a stroma-rich and hypoxic microenvironment (6). Then, intratumoral hypoxia fuels tumor progression by inducing angiogenesis, genomic instability, a switch to anaerobic metabolism, induction of a cancer 'stem cell' phenotype, EMT, metastasis, inflammation, fibrosis, immunosuppression, and resistance to apoptosis/autophagy and chemotherapy (33). Previous findings have shown that eradicating tumor stroma by targeted deletion leads to undifferentiated, aggressive pancreatic cancer, suggesting that tumor-associated fibroblasts may play an inhibitory role rather than a tumor-promoting role $(28,30)$. A possible reason for this phenomenon is that 

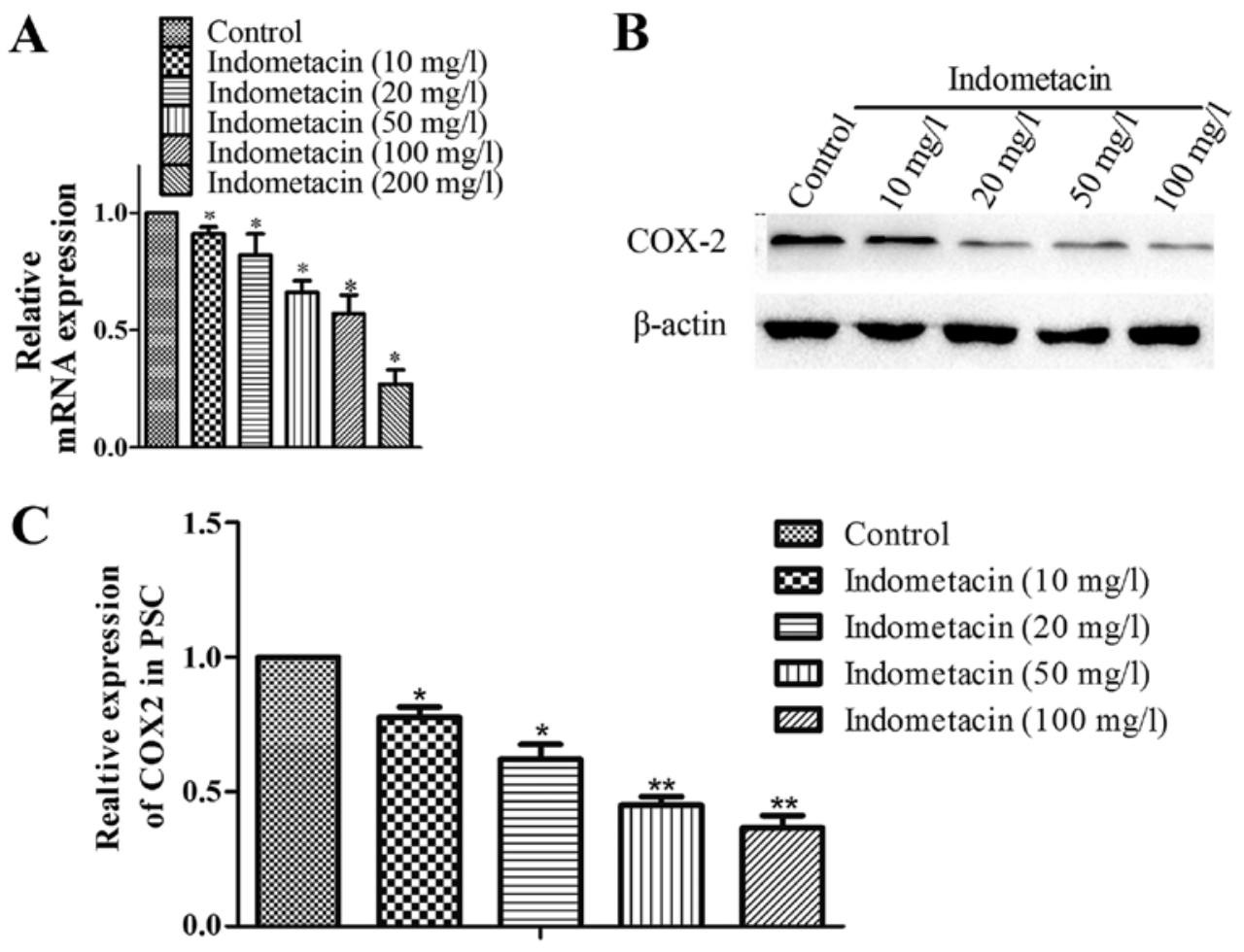

D
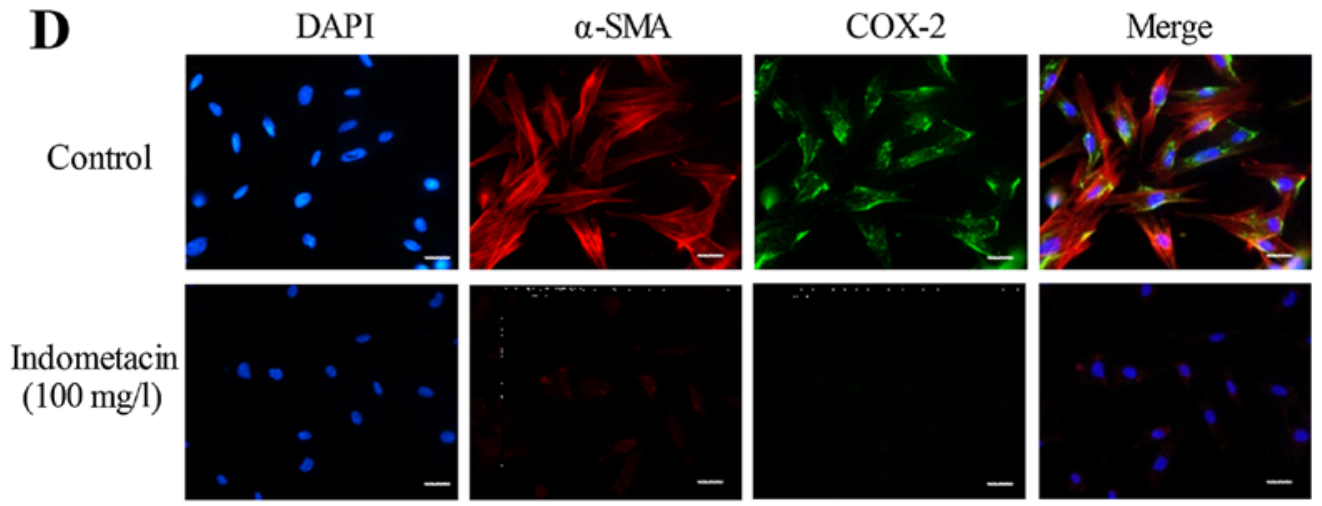

Figure 5. Indometacin decreases the COX-2 expression in hPSCs. (A) RT-qPCR results show that the mRNA level of COX-2 was decreased by indomethacin at various concentrations $(0,10,20,50,100$, and $200 \mathrm{mg} / \mathrm{l})$. ${ }^{*} \mathrm{P}<0.05$ compared with the control group. (B) Western blot analysis confirmed that COX-2 protein expression was inhibited by indometacin intervention in a dose-dependent manner. (C) A gray scanning analysis was performed to quantify the relative expression of COX-2 with regard to $\beta$-actin in Fig. $5 \mathrm{~B} .{ }^{*} \mathrm{P}<0.05,{ }^{* *} \mathrm{P}<0.01$ compared with the control group. The data shown are representative of three independent experiments. The mean values and standard deviations in the graphs are calculated from all three experiments with a total of 3 samples per treatment group. (D) Immunofluorescence shows that $\alpha$-SMA and COX-2 expression was decreased by indometacin in hPSCs. Scale bar, $50 \mu$ m; magnification, $\mathrm{x} 400$.

these cells likely exist to eliminate some key stromal components that are necessary for maintaining tissue homeostasis. However, the study of Sherman et al offers a new strategy to cure pancreatic cancer (34). Sherman et al (34) revealed that the vitamin D receptor (VDR) plays an important role in the activation of pancreatic stellate cells and that VDR activation by VDR ligand calcipotriol leads to stromal reprogramming, which includes reversing reactive stroma back to a quiescent state, thus reducing fibrosis-related inflammatory markers, decreasing energy supply for the tumor, restoring normal function, promoting chemotherapeutic efficacy and enhancing potential immune responses to pancreatic cancer. All-trans retinoic acid (ATRA) can also reverse activated PSCs into a resting state, thereby inhibiting the proliferation of cancer cells and $\beta$-catenin nuclear translocation, increasing tumor cell apoptosis and changing tumor morphology (35). As such, reversing activated PSCs back to the quiescent, vitamin-A-rich and lipid droplet-positive stromal cells that exist in healthy tissue is a new paradigm for treating pancreatic cancer.

Overexpression of COX-2 has been observed in 46 to $70 \%$ of pancreatic tumors $(13,36,37)$ and is mainly overexpressed in pancreatic carcinoma cells (38). Previous research also suggests that in chronic pancreatitis, COX-2 is of great significance in the initiation and promotion of pancreatic stellate cell activation (39). However, only a few studies have shown that COX-2 is expressed in pancreatic stellate cells, and those studies found no detectable COX-2 expression in the stroma of pancreatic cancer $(40,41)$. In the present study, double staining immunofluorescence revealed that the expression of COX-2 and $\alpha$-SMA in PSCs taken from tumor tissue was elevated with increasing culture time, which is in agreement with the findings of Charo et al (20), who showed that PSCs cultured 
in vitro express COX-2 and produce PGE2. PGE2, via its EP4 receptor, promotes a series of behavioral cellular changes, including increased proliferation, migration, and activation of PSCs and the synthesis of the collagen I matrix. In contrast to the findings of Charo et al (20), other authors found that PGE2 exerts inhibitory effects on the proliferation and fibrogenesis of PSCs through its receptor EP2, a process that is mediated by the cAMP pathway (41).

Drug 'repurposing' can be used to identify novel applications for drugs that have already been approved by the US FDA for another purpose. As drug repurposing can reduce the length and cost of research and avoid clinical trials, it is more affordable and achievable than novel drug discovery (42). Indometacin is a non-steroidal anti-inflammatory drug (NSAID) and is also a non-selective inhibitor of COX-2. Recently, treatment with indometacin has been shown to have effects against PDAC, while its effects on PSCs are largely unclear (25). Although the stroma plays an important role in PDAC progression, how stromal activity and downstream signaling are regulated at a molecular level has not been completely clarified. Reversing activated PSCs back to a quiescent state seems to be a promising strategy, and our study provides evidence that indometacin inhibits PSC activation and major behavior changes in PSCs. These changes include suppression of the activation, proliferation and migration of PSCs, and the underlying mechanism of this process may be through the inhibition COX-2. However, whether indometacin can reverse activated PSCs back to a quiescent state as well as the definite mechanism by which this occurs remains to be confirmed.

\section{Acknowledgements}

Not applicable.

\section{Funding}

The study was funded by the Clinical Innovation Funds of the 1st Affiliated Hospital of XJTU (no. 15ZD07) and the National Natural Science Foundation of China (nos. 81402971, 81672434 and 81702916).

\section{Available data and materials}

Not applicable.

\section{Author's contributions}

LS, QM and WD designed the experiments; LS carried out the majority of the experiments; $\mathrm{KC}$ and $\mathrm{ZJ}$ analyzed the data; XC and JM organized the figures; LS wrote the manuscript; QM and WD reviewed it. All authors read the final manuscript and agreed to publication.

\section{Ethics approval and consent to participate}

The experimental protocols were authorized by the Ethics Committee of the First Affiliated Hospital of Medical College, Xi'an Jiaotong University (Xi'an, China). The protocols also complied with the Declaration of Helsinki. Written informed consent was obtained from all the study participants.

\section{Consent for publication}

Not applicable.

\section{Competing interests}

There were no competing interests to declare.

\section{References}

1. Siegel RL, Miller KD and Jemal A: Cancer statistics, 2016. CA Cancer J Clin 66: 7-30, 2016.

2. Dvorak HF: Tumors: Wounds that do not heal. Similarities between tumor stroma generation and wound healing. N Engl J Med 315: 1650-1659, 1986.

3. Whatcott CJ, Diep CH, Jiang P, Watanabe A, LoBello J, Sima C, Hostetter G, Shepard HM, Von Hoff DD and Han H: Desmoplasia in primary tumors and metastatic lesions of pancreatic cancer. Clin Cancer Res 21: 3561-3568, 2015.

4. Stylianopoulos T, Martin JD, Chauhan VP, Jain SR, Diop-Frimpong B, Bardeesy N, Smith BL, Ferrone CR, Hornicek FJ, Boucher Y, et al: Causes, consequences, and remedies for growth-induced solid stress in murine and human tumors. Proc Natl Acad Sci USA 109: 15101-15108, 2012.

5. Chauhan VP, Boucher Y, Ferrone CR, Roberge S, Martin JD, Stylianopoulos T, Bardeesy N, DePinho RA, Padera TP, Munn LL and Jain RK: Compression of pancreatic tumor blood vessels by hyaluronan is caused by solid stress and not interstitial fluid pressure. Cancer Cell 26: 14-15, 2014.

6. Provenzano PP, Cuevas C, Chang AE, Goel VK, Von Hoff DD and Hingorani SR: Enzymatic targeting of the stroma ablates physical barriers to treatment of pancreatic ductal adenocarcinoma. Cancer Cell 21: 418-429, 2012.

7. Apte MV, Haber PS, Applegate TL, Norton ID, McCaughan GW, Korsten MA, Pirola RC and Wilson JS: Periacinar stellate shaped cells in rat pancreas: Identification, isolation, and culture. Gut 43: 128-133, 1998.

8. Phillips PA, McCarroll JA, Park S, Wu MJ, Pirola R, Korsten M, Wilson JS and Apte MV: Rat pancreatic stellate cells secrete matrix metalloproteinases: Implications for extracellular matrix turnover. Gut 52: 275-282, 2003.

9. Apte MV and Wilson JS: Dangerous liaisons: Pancreatic stellate cells and pancreatic cancer cells. J Gastroenterol Hepatol 27 (Suppl 2): S69-S74, 2012.

10. Bailey JM, Swanson BJ, Hamada T, Eggers JP, Singh PK, Caffery T, Ouellette MM and Hollingsworth MA: Sonic hedgehog promotes desmoplasia in pancreatic cancer. Clin Cancer Res 14: 5995-6004, 2008.

11. Hwang RF, Moore T, Arumugam T, Ramachandran V, Amos KD, Rivera A, Ji B, Evans DB and Logsdon CD: Cancer-associated stromal fibroblasts promote pancreatic tumor progression. Cancer Res 68: 918-926, 2008.

12. Fosslien E: Molecular pathology of cyclooxygenase-2 in neoplasia. Ann Clin Lab Sci 30: 3-21, 2000.

13. Schlosser W, Schlosser S, Ramadani M, Gansauge F, Gansauge S and Beger HG: Cyclooxygenase-2 is overexpressed in chronic pancreatitis. Pancreas 25: 26-30, 2002.

14. Tucker ON, Dannenberg AJ, Yang EK, Zhang F, Teng L, Daly JM, Soslow RA, Masferrer JL, Woerner BM, Koki AT and Fahey TJ III: Cyclooxygenase-2 expression is up-regulated in human pancreatic cancer. Cancer Res 59: 987-990, 1999.

15. Kokawa A, Kondo H, Gotoda T, Ono H, Saito D, Nakadaira S, Kosuge $\mathrm{T}$ and Yoshida $\mathrm{S}$ : Increased expression of cyclooxygenase-2 in human pancreatic neoplasms and potential for chemoprevention by cyclooxygenase inhibitors. Cancer 91: 333-338, 2001.

16. Koshiba T, Hosotani R, Miyamoto Y, Wada M, Lee JU, Fujimoto K, Tsuji S, Nakajima S, Doi R and Imamura M: Immunohistochemical analysis of cyclooxygenase-2 expression in pancreatic tumors. Int J Pancreatol 26: 69-76, 1999.

17. Merati K, Said Siadaty M, Andea A, Sarkar F, Ben-Josef E, Mohammad R, Philip P, Shields AF, Vaitkevicius V, Grignon DJ and Adsay NV: Expression of inflammatory modulator COX-2 in pancreatic ductal adenocarcinoma and its relationship to pathologic and clinical parameters. Am J Clin Oncol 24: 447-452, 2001. 
18. Maitra A, Ashfaq R, Gunn CR, Rahman A, Yeo CJ, Sohn TA, Cameron JL, Hruban RH and Wilentz RE: Cyclooxygenase 2 expression in pancreatic adenocarcinoma and pancreatic intraepithelial neoplasia: An immunohistochemical analysis with automated cellular imaging. Am J Clin Pathol 118: 194-201, 2002.

19. Philip B, Roland CL, Daniluk J, Liu Y, Chatterjee D, Gomez SB, Ji B, Huang $\mathrm{H}$, Wang $\mathrm{H}$, Fleming JB, et al: A high-fat diet activates oncogenic Kras and COX2 to induce development of pancreatic ductal adenocarcinoma in mice. Gastroenterology 145 : 1449-1458, 2013.

20. Charo C, Holla V, Arumugam T, Hwang R, Yang P, Dubois RN, Menter DG, Logsdon CD and Ramachandran V: Prostaglandin E2 regulates pancreatic stellate cell activity via the EP4 receptor. Pancreas 42: 467-474, 2013.

21. Kubatka P, Kalická K, Bojková B, Ahlers I, Ahlersová E and PéčM:NeoplasticeffectofindomethacininN-methyl-N-nitrosourea induced mammary carcinogenesis in female rats. Klin Onkol 25 : 359-363, 2012 (In Slovak).

22. Lange A,GustkeH,GlassmeierG,HeineM,Zangemeister-WittkeU, Schwarz JR, Schumacher U and Lange T: Neuronal differentiation by indomethacin and IBMX inhibits proliferation of small cell lung cancer cells in vitro. Lung Cancer 74: 178-187, 2011.

23. de Groot DJ, van der Deen M, Le TK, Regeling A, de Jong S and de Vries EG: Indomethacin induces apoptosis via a MRP1-dependent mechanism in doxorubicin-resistant small-cell lung cancer cells overexpressing MRP1. Br J Cancer 97: 1077-1083, 2007.

24. Das A, Banik NL and Ray SK: Methylprednisolone and indomethacin inhibit oxidative stress mediated apoptosis in rat C6 glioblastoma cells. Neurochem Res 32: 1849-1856, 2007.

25. Han L, Peng B, Ma Q, Ma J, Li J, Li W, Duan W, Chen C, Liu J, $\mathrm{Xu} \mathrm{Q}$, et al: Indometacin ameliorates high glucose-induced proliferation and invasion via modulation of e-cadherin in pancreatic cancer cells. Curr Med Chem 20: 4142-4152, 2013.

26. Gao Z, Wang X, Wu K, Zhao Y and Hu G: Pancreatic stellate cells increase the invasion of human pancreatic cancer cells through the stromal cell-derived factor-1/CXCR4 axis. Pancreatology 10 186-193, 2010.

27. Bachem MG, Schneider E, Gross H, Weidenbach H, Schmid RM, Menke A, Siech M, Beger H, Grünert A and Adler G: Identification, culture, and characterization of pancreatic stellate cells in rats and humans. Gastroenterology 115: 421-432, 1998.

28. Rhim AD, Oberstein PE, Thomas DH, Mirek ET, Palermo CF, Sastra SA, Dekleva EN, Saunders T, Becerra CP, Tattersall IW, et al: Stromal elements act to restrain, rather than support, pancreatic ductal adenocarcinoma. Cancer Cell 25: 735-747, 2014.

29. Schmittgen TD and Livak KJ: Analyzing real-time PCR data by the comparative C(T) method. Nat Protoc 3: 1101-1108, 2008.

30. Özdemir BC, Pentcheva-Hoang T, Carstens JL, Zheng X, Wu CC, Simpson TR, Laklai H, Sugimoto H, Kahlert C, Novitskiy SV, et al: Depletion of carcinoma-associated fibroblasts and fibrosis induces immunosuppression and accelerates pancreas cancer with reduced survival. Cancer Cell 25: 719-734, 2014
31. Pandol S,Edderkaoui M, Gukovsky I,Lugea A and Gukovskaya A: Desmoplasia of pancreatic ductal adenocarcinoma. Clin Gastroenterol Hepatol 7 (11 Suppl): S44-S47, 2009.

32. Schober M, Jesenofsky R, Faissner R, Weidenauer C, Hagmann W, Michl P, Heuchel RL, Haas SL and Löhr JM: Desmoplasia and chemoresistance in pancreatic cancer. Cancers 6: 2137-2154, 2014.

33. Jain RK: Antiangiogenesis strategies revisited: From starving tumors to alleviating hypoxia. Cancer Cell 26: 605-622, 2014.

34. Sherman MH, Yu RT, Engle DD, Ding N, Atkins AR, Tiriac H, Collisson EA, Connor F, Van Dyke T, Kozlov S, et al: Vitamin D receptor-mediated stromal reprogramming suppresses pancreatitis and enhances pancreatic cancer therapy. Cell 159: 80-93, 2014.

35. Froeling FE, Feig C, Chelala $\mathrm{C}$, Dobson R, Mein CE, Tuveson DA, Clevers H, Hart IR and Kocher HM: Retinoic acid-induced pancreatic stellate cell quiescence reduces paracrine Wnt- $\beta$-catenin signaling to slow tumor progression. Gastroenterology 141: 1486-1497, e1-e14, 2011.

36. Okami J, Yamamoto H, Fujiwara Y, Tsujie M, Kondo M, Noura S, Oshima S, Nagano H, Dono K, Umeshita K, et al: Overexpression of cyclooxygenase- 2 in carcinoma of the pancreas. Clin Cancer Res 5: 2018-2024, 1999.

37. Yip-Schneider MT, Barnard DS, Billings SD, Cheng L, Heilman DK, Lin A, Marshall SJ, Crowell PL, Marshall MS and Sweeney CJ: Cyclooxygenase-2 expression in human pancreatic adenocarcinomas. Carcinogenesis 21: 139-146, 2000.

38. Colby JK, Klein RD, McArthur MJ, Conti CJ, Kiguchi K, Kawamoto T, Riggs PK, Pavone AI, Sawicki J and Fischer SM: Progressive metaplastic and dysplastic changes in mouse pancreas induced by cyclooxygenase-2 overexpression. Neoplasia 10: 782-796, 2008

39. Aoki H, Ohnishi H, Hama K, Shinozaki S, Kita H, Osawa H, Yamamoto H, Sato K, Tamada K and SuganoK: Cyclooxygenase-2 is required for activated pancreatic stellate cells to respond to proinflammatory cytokines. Am J Physiol Cell Physiol 292: C259-C268, 2007.

40. Gong J, Xie J, Bedolla R, Rivas P, Chakravarthy D, Freeman JW, Reddick R, Kopetz S, Peterson A, Wang H, et al: Combined targeting of STAT3/NF- $\mathrm{B} / \mathrm{COX}-2 / \mathrm{EP} 4$ for effective management of pancreatic cancer. Clin Cancer Res 20: 1259-1273, 2014.

41. Pomianowska E, Sandnes D, Grzyb K, Schjølberg AR, Aasrum M, Tveteraas IH, Tjomsland V, Christoffersen T and Gladhaug IP: Inhibitory effects of prostaglandin E2 on collagen synthesis and cell proliferation in human stellate cells from pancreatic head adenocarcinoma. BMC Cancer 14: 413, 2014.

42. Pessetto ZY, Weir SJ, Sethi G, Broward MA and Godwin AK: Drug repurposing for gastrointestinal stromal tumor. Mol Cancer Ther 12: 1299-1309, 2013. 